\title{
The Influence of Pores on Irradiation Property of Selected Nuclear Graphites
}

\author{
Zhengcao Li, ${ }^{1}$ Dongyue Chen, ${ }^{1}$ Xiaogang Fu, ${ }^{1,2}$ Wei Miao, ${ }^{1}$ and Zhengjun Zhang ${ }^{1}$ \\ ${ }^{1}$ State Key Laboratory of New Ceramic and Fine Processing, Department of Materials Science and Engineering, Tsinghua University, \\ Beijing 100084, China \\ ${ }^{2}$ Fast Breed Reactor Division, China Institute of Atomic Energy, Beijing 102413, China
}

Correspondence should be addressed to Zhengcao Li, zcli@tsinghua.edu.cn

Received 8 May 2011; Revised 3 August 2011; Accepted 5 August 2011

Academic Editor: Koumei Baba

Copyright (C) 2012 Zhengcao Li et al. This is an open access article distributed under the Creative Commons Attribution License, which permits unrestricted use, distribution, and reproduction in any medium, provided the original work is properly cited.

\begin{abstract}
As structural material and moderator in high temperature gas-cooled reactor (HTGR), nuclear graphite endures large flux of irradiation in its service time. The microstructure of nuclear graphite is a topical issue studied to predict the irradiation property of graphite and improve manufacturing process. In our present work, the pores in graphite are focused, and the relationship between pore and irradiation behavior is discussed. Three kinds of nuclear graphite (IG-11, NBG-18, and HSM-SC) are concerned, and their porosity, pore size, and morphology before and after irradiation are studied, respectively. A comparison between the three graphites shows that dense small pores which are uniformly distributed in graphite bring better irradiation property because the pores can accommodate some of the internal stress caused by irradiation expansion. Coke particles of small size and a thorough mixture between coke and binder are suggested to obtain such pores in nuclear graphite and thus improve irradiation property.
\end{abstract}

\section{Introduction}

The rapid development of high temperature gas-cooled reactor (HTGR) boosts the study of isotropic graphite. Due to its low neutron absorption cross-section, corrosion resistance, and good mechanical properties at high temperature, graphite is used as structural material and moderator to thermalize fast neutrons from the fission process $[1,2]$. But the environment of neutron irradiation in reactors during operation inevitably induces changes in dimension and physical properties to graphite, promoting stress and even cracks [2-4]. The behavior of graphite under irradiation needs to be carefully studied to ensure the safety of reactors during its service time.

The pores or cracks in graphite play an important role in graphite irradiation property. Mrozowski put forward that some pores are closed to counteract the c-axis expansion under high-temperature irradiation [5]. Pedraza and Koike proved Mrozowski's theory in 1993 under in situ transmission electron microscope (TEM), classified microcracks into two types, and, respectively, described their behaviors under irradiation [6]. The process of pore generation under irradiation is then discovered [7].

In this work, we focus on the relationship between microstructures and graphite irradiation property. The way that pores affect the behavior of graphite under irradiation has been studied.

\section{Experimental}

Three types of graphites were conducted in the present work, that is, IG-11 (Toyo Tanso Co.), NBG-18 (SGL Group), and HSM-SC (Rong Guang). And their characteristics are listed in Table 1.

The mercury porosimetry used here to measure pore diameter in graphite is AutoPore IV 9500 produced by Micromeritics Instrument Corporation, with a measuring range between 300 and $150000 \AA$ and mercury intrusion and extrusion volumes better than $0.1 \mu \mathrm{L}$.

Samples are polished before observation under metalloscope and were irradiated by $\mathrm{He}^{+}$and $\mathrm{Xe}^{+}$at room temperature. 
TABle 1: Characteristics of three nuclear graphites chosen for the present study.

\begin{tabular}{lccc}
\hline & IG-11 & NBG-18 & HSM-SC \\
\hline $\begin{array}{l}\text { Coke } \\
\begin{array}{l}\text { Average coke } \\
\text { diameter }(\mu \mathrm{m})\end{array}\end{array}$ & Petrol coke & Pitch coke & Petrol coke \\
Compaction & $\begin{array}{c}\text { Isostatic } \\
\text { compaction }\end{array}$ & $\begin{array}{c}\text { Vibratory } \\
\text { compaction }\end{array}$ & $\begin{array}{c}\text { Isostatic } \\
\text { compaction }\end{array}$ \\
\hline
\end{tabular}

TABLE 2: The apparent density and porosity of the three graphite samples.

\begin{tabular}{lccc}
\hline & IG-11 & NBG-18 & HSM-SC \\
\hline Apparent density $\left(\mathrm{g} / \mathrm{cm}^{3}\right)$ & 1.77 & 1.86 & 1.84 \\
Porosity $(\%)$ & 20.8 & 17.3 & 18.2 \\
\hline
\end{tabular}

\section{Results and Discussion}

3.1. Porosity. The total porosity of graphite can be calculated by the following simple equation [8]:

$$
\varepsilon=\left(1-\frac{d_{V}}{2.25}\right) \times 100 \%
$$

where $d_{V}$ is the apparent density of graphite, and $2.25\left(\mathrm{~g} / \mathrm{cm}^{3}\right)$ is the theoretical density of single-crystal graphite. Table 2 shows the calculation results of the three graphite samples. They share similar porosity around $20 \%$.

To further understand the distribution of pores in graphite, both mercury porosimetry and metalloscope are used. Figure 1 illustrates the distribution of pore diameters of the three samples. The pores in IG-11 are small, with pore diameters mainly around $1.5 \sim 3 \mu \mathrm{m}$, whereas pores in HSM-SC have a sharp peak of $2 \sim 4 \mu \mathrm{m}$, just a little bigger than IG11. NBG-18 is quite different from both IG-11 and HSM-SC, with pore diameters scattered in a wide range of $5 \sim 35 \mu \mathrm{m}$, and has a gradual rise around $25 \mu \mathrm{m}$. In other words, though sharing quite similar total porosity, NBG-18 has pores much larger than IG-11 or HSM-SC.

A parallel result could be drawn from the metalloscope images of the samples, shown in Figure 2. The morphology of pores in IG-11 and HSM-SC is quite the same, both small in size and large in quantity, whereas the pores in NBG-18 are apparently bigger and sparsely spread, reaching a diameter of several tens of microns and even more.

Moreover, the pore difference between IG-11 and HSMSC should also be noted, shown in Figure 3. The small size pores are not uniformly distributed in HSM-SC, which means that in some areas of HSM-SC, pores tend to appear together and form a sort of pore clusters (Figure 3(c)), while in some other areas, only a few pores could be observed (Figure $3(\mathrm{~d})$ ). Pores in IG-11 are distributed much more uniformly and evenly than in HSM-SC.

The nonuniform pore distribution of HSM-SC could also be illustrated by counting the aberrantly large pores on graphite surface. In the $12 \times 21 \mathrm{~mm}^{2}$ surface area of graphite sample, IG-11 has 14 pores with diameters larger than

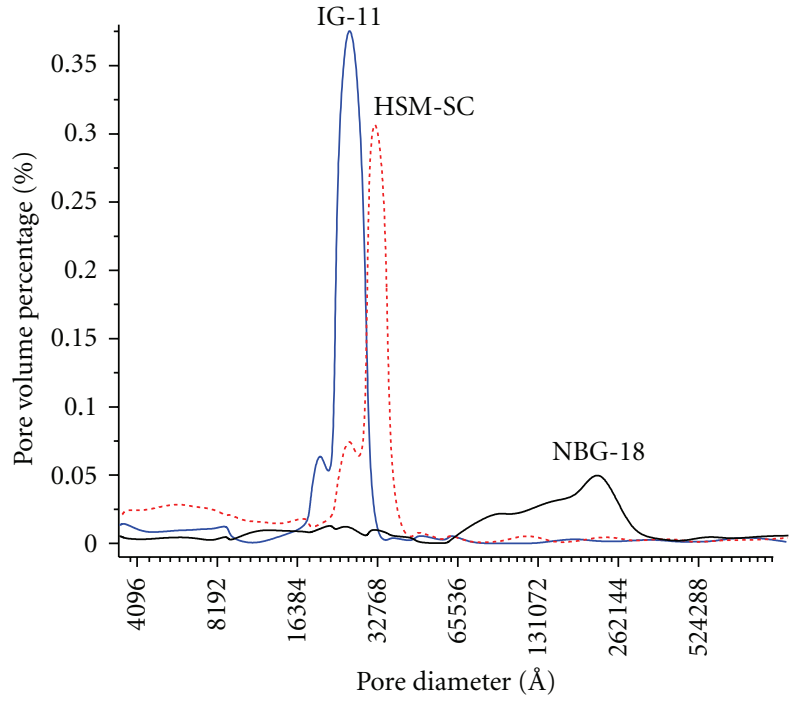

Figure 1: Pore diameter distribution of the graphite samples.

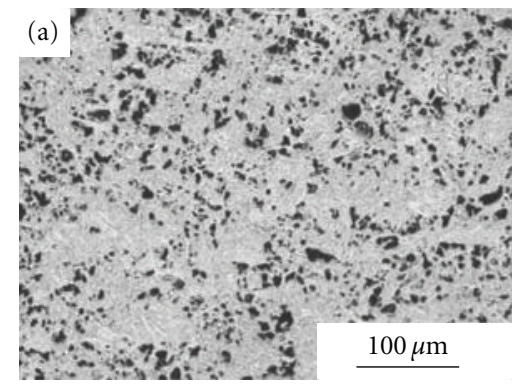

(a)

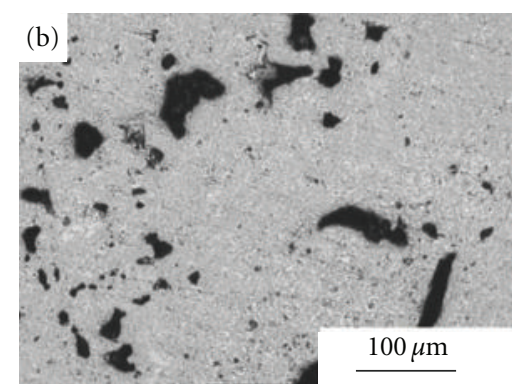

(b)

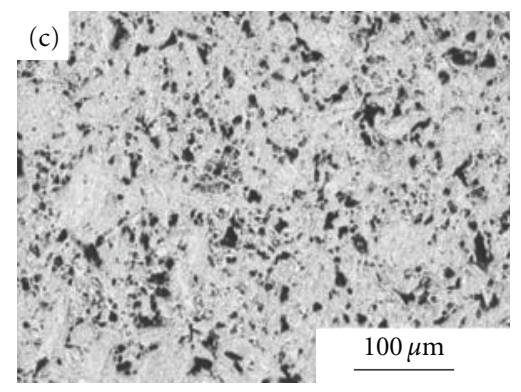

(c)

FIGURE 2: Morphology of graphite samples before irradiation. (a) IG-11, (b) NBG-18, and (c) HSM-SC. 


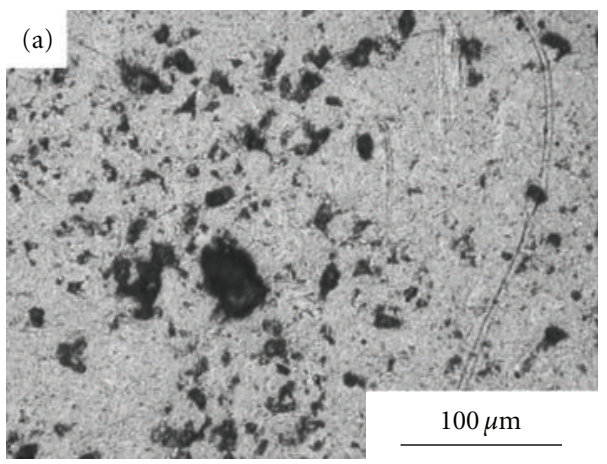

(a)

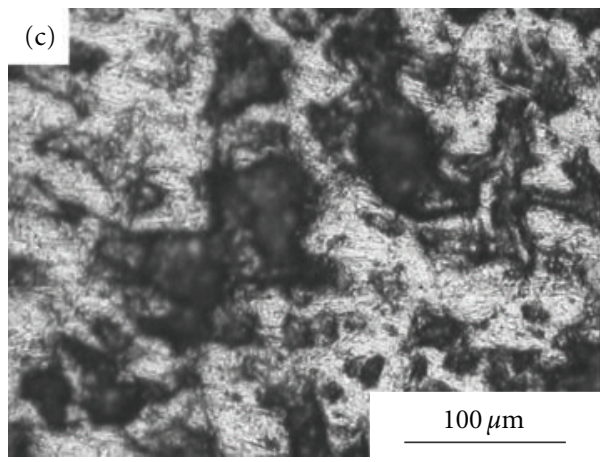

(c)

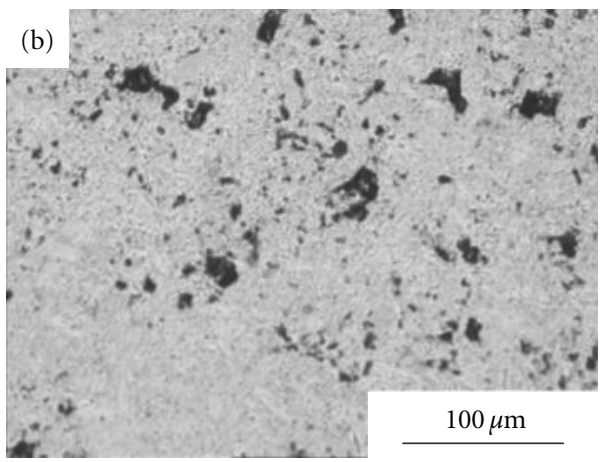

(b)

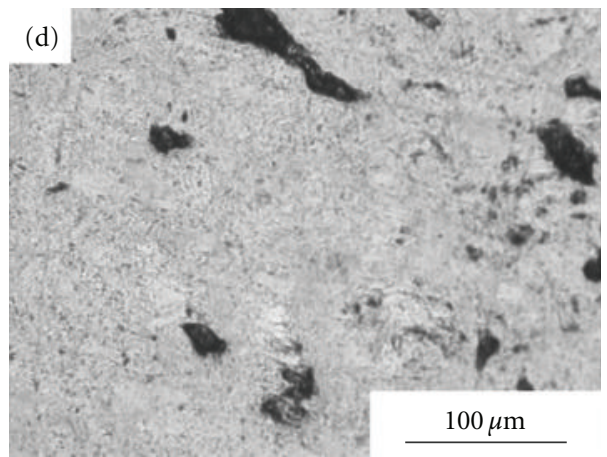

(d)

FIGURE 3: Graphite morphology before irradiation. (a) Porous region; (b) few pores region in IG-11; (c) porous region; (d) few pores region in HSM-SC.

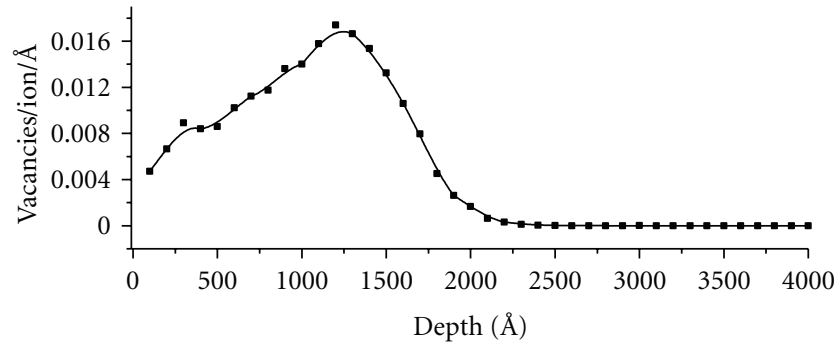

(a)

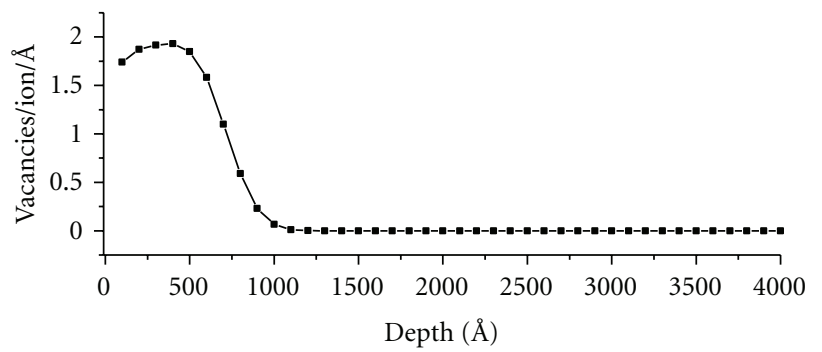

(b)

FIGURE 4: SRIM simulation of vacancy depth distribution under 10000 ion irradiation of (a) $20 \mathrm{keV} \mathrm{He}^{+}$, (b) $200 \mathrm{keV} \mathrm{Xe}^{+}$.

$150 \mu \mathrm{m}$, and the maximum diameter is about $200 \mu \mathrm{m}$; HSMSC has 31 pores bigger than $200 \mu \mathrm{m}$, with maximum diameter reaching up to $330 \mu \mathrm{m}$.

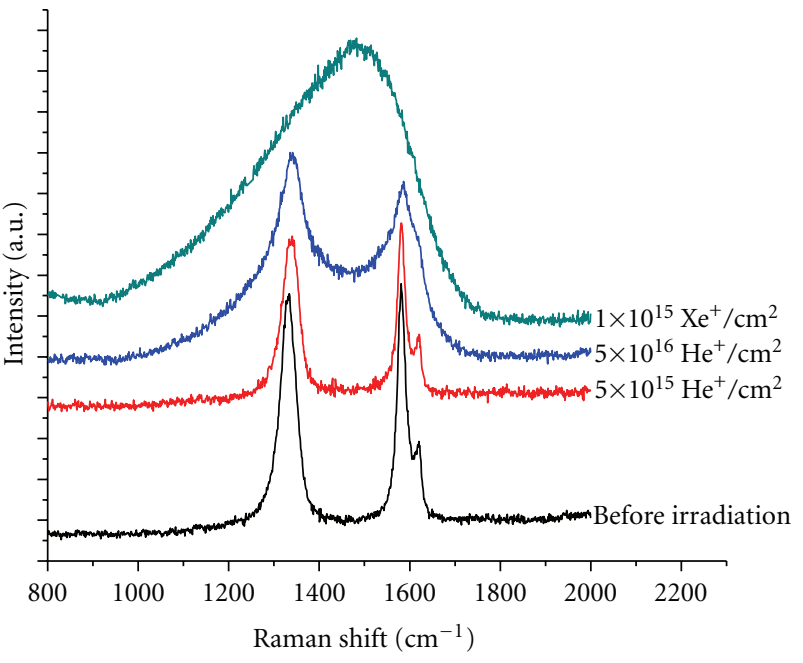

FIGURE 5: Raman spectra of IG-11.

\section{Irradiation Property}

Since neutron irradiation is really expensive and time consuming, the use of ion irradiation could be a good choice for damage simulation, as it accelerates the process of irradiation damage and compresses irradiation time from years to hours. Though sputtering is introduced as heavy ions bombard the surface of graphite samples, the order of irradiation 


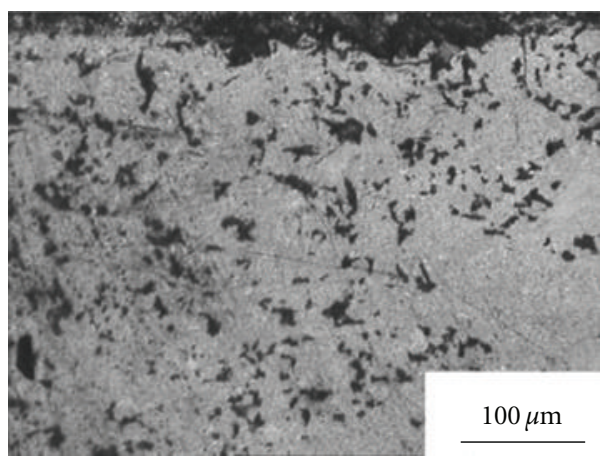

(a)

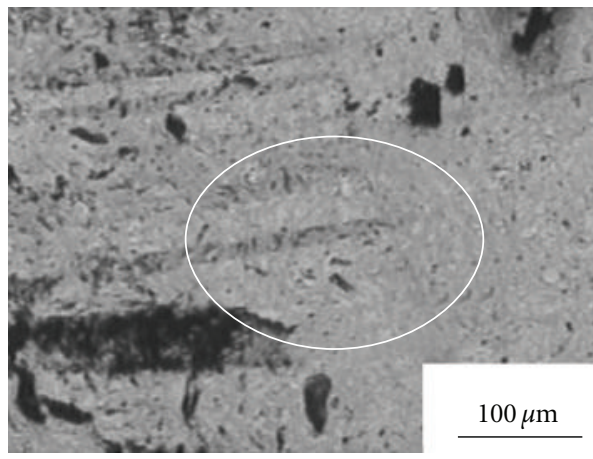

(c)

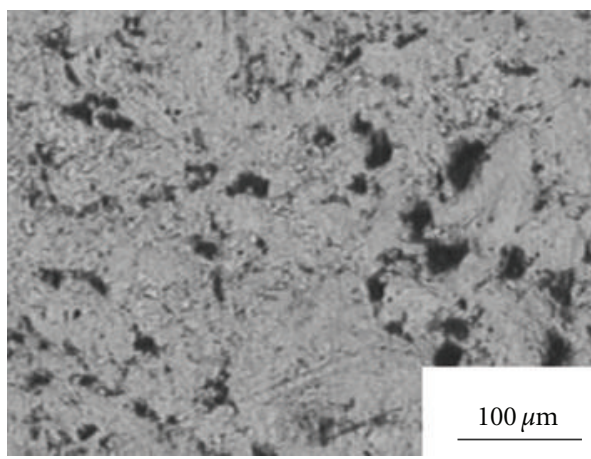

(e)

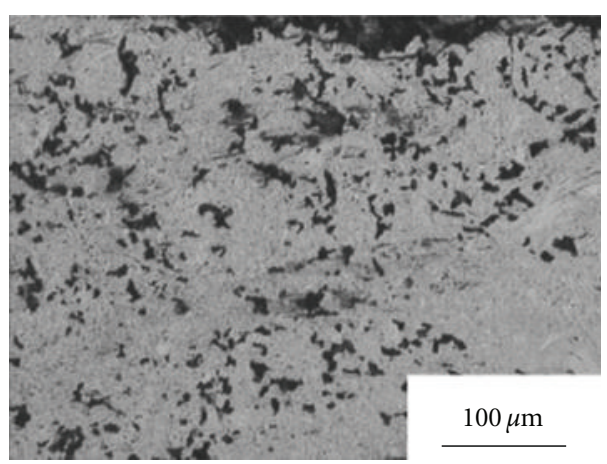

(b)

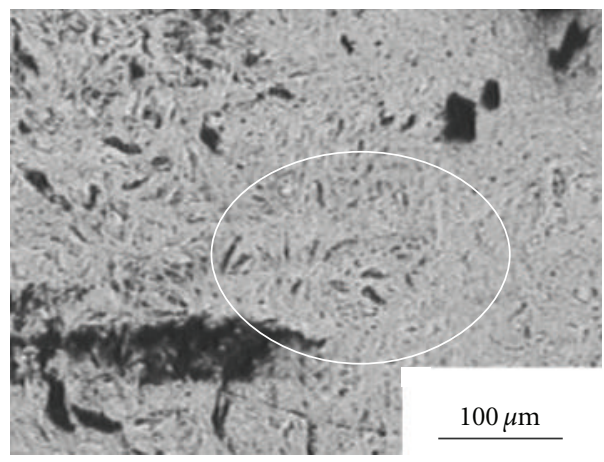

(d)

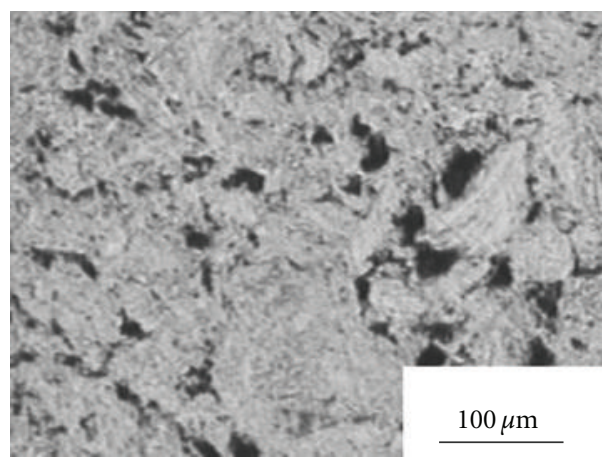

(f)

FIGURE 6: Graphite morphology before and after $20 \mathrm{keV} \mathrm{He}{ }^{+}$irradiation with flux of $5 \times 10^{16}$ ions/cm ${ }^{2}$. (a) IG-11, (c) NBG18, and (e) HSM-SC before irradiation; (b) IG-11, (d) NBG18, and (f) HSM-SC after irradiation.

properties of the three samples could still be determined by their morphology, as long as they are irradiated under the same condition. Since the damage induced by $20 \mathrm{keV} \mathrm{He}{ }^{+}$ irradiation is found to be quite light in our experiment, the $\mathrm{Xe}^{+}$irradiation, the kind of heavy ion irradiation which is commonly used to study irradiation defects, is also introduced in the present work [9-11].

Software SRIM 2008 (stopping and range of ions in matter 2008) can calculate the depth distribution of vacancies that ion irradiation may cause in selected material [12], and it is applied here to simulate $\mathrm{He}^{+}$and $\mathrm{Xe}^{+}$irradiation, shown in Figure 4 . The defects brought by $\mathrm{He}^{+}$and $\mathrm{Xe}^{+}$irradiation are just near sample surface, and thus the surface structure change can be detected by Raman measurements, since the effective penetration depth of laser light is calculated to be about $175 \mathrm{~nm}$ in our experiment.
There are three peaks in the Raman spectra of unirradiated graphite: $1355 \mathrm{~cm}^{-1}, 1580 \mathrm{~cm}^{-1}$ and $1620 \mathrm{~cm}^{-1}$. $1580 \mathrm{~cm}^{-1}$ peak (G-peak) is the characteristic peak of graphite, while $1620 \mathrm{~cm}^{-1}$ peak represents point defects in graphite, and $1355 \mathrm{~cm}^{-1}$ peak (D-peak) comes from defects and random orientation of grains in graphite [13]. After irradiation, the crystal structure of graphite surface is destroyed, resulting in the change of phonon-vibrating frequency, and thus the broadening and even overlapping of G-peak and D-peak in Raman spectra.

Figure 5 shows the Raman spectra of IG-11 before and after ion irradiation. No specific change is observed after $20 \mathrm{keV} \mathrm{He} e^{+}$irradiation at flux of $5 \times 10^{15} \mathrm{ions} / \mathrm{cm}^{2}$, but G-peak and D-peak are both broadened if flux is increased to $5 \times 10^{16}$ ions $/ \mathrm{cm}^{2}$, showing that defects in graphite are generated due to the large flux of $\mathrm{He}^{+}$irradiation. 


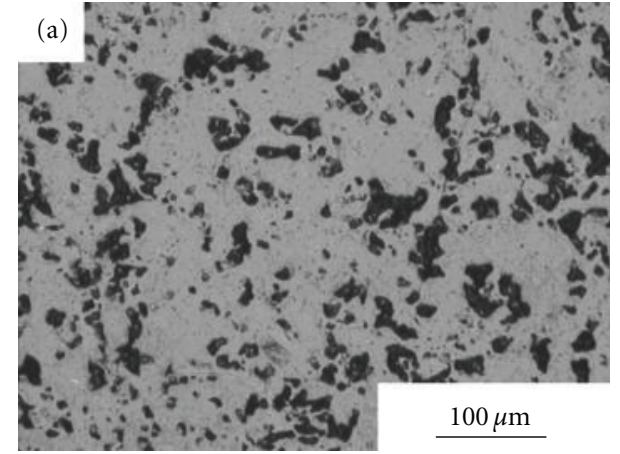

(a)

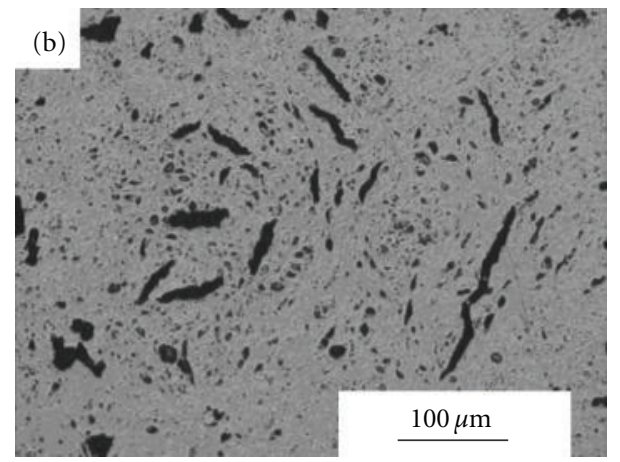

(b)

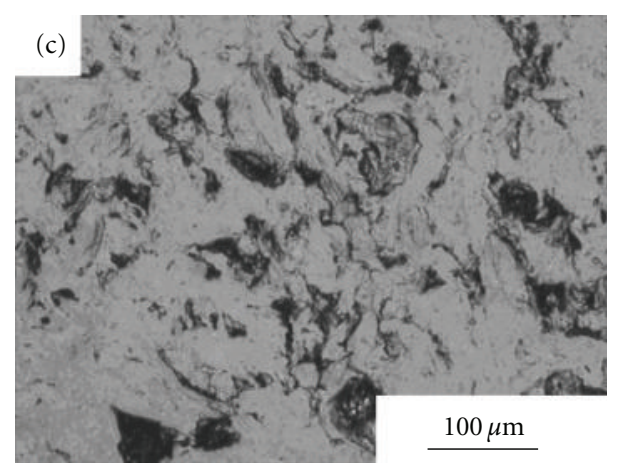

(c)

FIgURE 7: Graphite morphology after $200 \mathrm{keV} \mathrm{Xe}$ irradiation with flux of $1 \times 10^{14}$ ions $/ \mathrm{cm}^{2}$. (a) IG-11; (b) NBG-18; (c) HSM-SC.

The overlapping of peaks appears in $200 \mathrm{keV} \mathrm{Xe} \mathrm{Xi}^{+}$irradiation at flux of $1 \times 10^{15}$ ions $/ \mathrm{cm}^{2}$, which indicates much heavier destruction of structure. The Raman spectra of NBG-18 and HSM-SC give similar conclusion.

Three-sample morphology before and after $\mathrm{He}^{+}$irradiation is also observed under metalloscope, and for HSM-SC, a region with uniformly distributed pores is selected to avoid pore clusters, shown in Figure 6 . The samples are irradiated with ion flux of $5 \times 10^{16}$ ions $/ \mathrm{cm}^{2}$ at the energy of $20 \mathrm{keV}$. Though $\mathrm{He}^{+}$irradiation of this flux causes structure damage on the surface of graphite samples (as shown in Figure 5), no obvious morphology change caused by irradiation could be found in IG-11 and HSM-SC. But for NBG-18, many small new pores form after irradiation. The generation of such micrometric scale cracks in graphite is also observed by Watanabe et al. under $\mathrm{N}^{+}$irradiation [14].
These new pores are not generated near already existing pores but are quite evenly distributed in the area used to have few pores. NBG-18 is the only one of the three to generate many new visible pores although the three samples share similar total porosity and all suffers crystal structure damage after this flux of irradiation.

Graphite microcrystal would expand in c-axis and shrink in a-axis under irradiation, which remarkably increases internal stress and may generate microcracks or pores in the graphite [15]. But the existing pores in graphite can be closed by increasing internal stress, which actually reliefs some stress caused by irradiation. New pores will not appear until these accommodating pores are consumed [16].

IG-11 and HSM-SC have small pores with diameter around $1.5 \sim 4 \mu \mathrm{m}$ spreading densely on the graphite surface (Figures 1 and 2). They do suffer irradiation damage as shown in Figure 5, but the damage induced by $20 \mathrm{keV} \mathrm{He}^{+}$ irradiation at flux of $1 \times 10^{16}$ ions $/ \mathrm{cm}^{2}$ is relatively light (compared to $\mathrm{Xe}^{+}$irradiation). Thus, these pores in the surface area can act as a sort of buffer to absorb internal stress caused by this level of irradiation damage, and both surfaces of IG-11 and HSM-SC with quite uniform pore distribution avoid generating visible new pores. But for NBG-18, pores are large and sparsely spread. Thus, in many regions of NBG18 , no pore exists to accommodate internal stress, and new pores appear exactly on these places after irradiation because of the accumulation of too much stress (Figure 6).

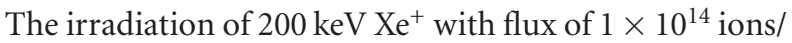
$\mathrm{cm}^{2}$ is also conducted in our experiment, shown in Figure 7. Though the flux of $\mathrm{Xe}^{+}$irradiation is two orders less than that of $\mathrm{He}^{+}$, the damage is much more severe (compared to unirradiated graphite in Figure 2), indicating that $\mathrm{Xe}^{+}$irradiation may be a good way to study heavy irradiation damage, while $\mathrm{He}^{+}$irradiation is a tool to simulate the first stage of damage.

The heavy ion $\mathrm{Xe}^{+}$generates and enlarges pores in IG-11 and NBG-18, but for HSM-SC, due to the nonuniform distribution of pores, pores in pore clusters easily get interconnected (Figure $7(\mathrm{c})$ ). Interconnected pores are a sign of degradation on physical properties, such as strength and elastic modulus [4]. Though pore interconnection does not happen in every region of HSM-SC after irradiation, HSMSC surely has the worst irradiation property of the three, since materials tend to break at the weakest point.

The present experiment shows that small-size pores which are both densely and uniformly distributed can improve the irradiation property of nuclear graphite. The morphology of pores in graphite results from the specific coke and binder selected in manufacturing and the process of mixture. The common sources of porosity in graphite manufacturing are coke calcination cracks, gas-evolution pores, and Mrozowski cracks formed during cooling from graphitization temperatures [17]. The first kind of pores appears in coke and is usually elongated in size, while the later two appear in binder phase and are small and round [18]. Judging from morphology, the large-size pores in NBG-18 are mostly calcinations cracks. These coke calcination cracks can be so large in NBG-18 because NBG-18 uses $300 \mu \mathrm{m}$ coke particles as raw material, while IG-11 and HSM-SC use only 
20 or $25 \mu \mathrm{m}$ coke particles which cannot contain such big calcination cracks (Table 2).

Similarly, since coke and binder phase contain pores of different size and morphology, a heterogeneous mixture of them may lead to the nonuniform pore distribution in HSMSC. Japanese researchers lay emphasis on the importance of a fine and homogeneous structure in isotropic graphite manufacturing and admit that their use of small-size coke particles makes it difficult to mix coke and pitch binder well [19], which is also the case for HSM-SC.

\section{Conclusion}

The way that pores affect irradiation property of nuclear graphite has been studied in the present work through $\mathrm{He}^{+}$ and $\mathrm{Xe}^{+}$irradiation. Dense small pores which are uniformly spread in graphite bring better irradiation property because the pores can accommodate some of the internal stress caused by irradiation expansion. And the use of small-size coke particles and a thorough mixture of coke and pitch can help obtain such small dense pores in nuclear graphite and thus improve irradiation property.

\section{Acknowledgments}

The authors are grateful to have the financial support of the National Natural Science Foundation of China (61076003) and the National Basic Research Program of China (973 program, 2010CB731600 and 2010CB832900).

\section{References}

[1] E. L. Fuller and J. M. Okoh, "Kinetics and mechanisms of the reaction of air with nuclear grade graphites: IG-110," Journal of Nuclear Materials, vol. 240, no. 3, pp. 241-250, 1997.

[2] Y. S. Lim, S. H. Chi, and K. Y. Cho, "Change of properties after oxidation of IG-11 graphite by air and $\mathrm{CO}_{2}$ gas," Journal of Nuclear Materials, vol. 374, no. 1-2, pp. 123-128, 2008.

[3] L. Babout, P. M. Mummery, T. J. Marrow, A. Tzelepi, and P. J. Withers, "The effect of thermal oxidation on polycrystalline graphite studied by X-ray tomography," Carbon, vol. 43, no. 4, pp. 765-774, 2005.

[4] G. B. Neighbour and P. J. Hacker, "The variation of compressive strength of AGR moderator graphite with increasing thermal weight loss," Materials Letters, vol. 51, no. 4, pp. 307$314,2001$.

[5] S. Mrozowski, Proceedings of the First and Second Conferences on Carbon, University of Buffalo, New York, NY, USA, 1956.

[6] D. F. Pedraza and J. Koike, "Dimensional changes in grade H451 nuclear graphite due to electron irradiation," Carbon, vol. 32, no. 4, pp. 727-734, 1994.

[7] G. B. Neighbour, "Modelling of dimensional changes in irradiated nuclear graphites," Journal of Physics D, vol. 33, no. 22, pp. 2966-2972, 2000.

[8] S. H. Chi and G. C. Kim, "Comparison of $3 \mathrm{MeV} \mathrm{C}+$ ionirradiation effects between the nuclear graphites made of pitch and petroleum cokes," Journal of Nuclear Materials, vol. 381, no. 1-2, pp. 98-105, 2008.

[9] Z. C. Li, D. P. Yu, and B. X. Liu, "Manipulation of ordered layered structures by interface-assisted ion-beam mixing in immiscible Ag-Co and Ag-Ni systems," Physical Review B, vol. 65, no. 24, Article ID 245403, 2002.
[10] Y. Hu, Z. C. Li, and Z. J. Zhang, "Irradiation induced localized amorphization in Mo-Re alloy films," Materials Transactions, vol. 51, no. 4, pp. 670-674, 2010.

[11] Y. Hu, Z. C. Li, and Z. J. Zhang, "Ion-implantation-induced patterns formation on silicon substrates," Physica E, vol. 41, no. 5, pp. 833-837, 2009.

[12] Z. C. Li, H. Abe, and N. Sekimura, "Detection of point defects upon ion irradiation by means of precipitate coherency," Journal of Nuclear Materials, vol. 362, no. 1, pp. 87-92, 2007.

[13] H. W. Willes and M. Roberto, Raman Scattering in Material Science, Springer, New York, NY, USA, 2000.

[14] H. Watanabe, K. Takahashi, and M. Iwaki, "Structural characterization of ion implanted pyrolytic graphite," Nuclear Instruments and Methods in Physics Research B, vol. 257, no. 1-2, pp. 549-553, 2007.

[15] D. K. L. Tsang and B. J. Marsden, "Effects of dimensional change strain in nuclear graphite component stress analysis," Nuclear Engineering and Design, vol. 237, no. 9, pp. 897-904, 2007.

[16] M. R. Bradford and A. G. Steer, "A structurally-based model of irradiated graphite properties," Journal of Nuclear Materials, vol. 381, no. 1-2, pp. 137-144, 2008.

[17] G. Hall, B. J. Marsden, and S. L. Fok, "The microstructural modelling of nuclear grade graphite," Journal of Nuclear Materials, vol. 353, no. 1-2, pp. 12-18, 2006.

[18] K. Y. Wen, T. J. Marrow, and B. J. Marsden, "The microstructure of nuclear graphite binders," Carbon, vol. 46, no. 1, pp. 62-71, 2008.

[19] The Carbon Society of Japan, "Elementary course to new carbon materials, Specialized Commission of Carbon Materials under the Chinese Metal Society trans \& edit," 1999. 

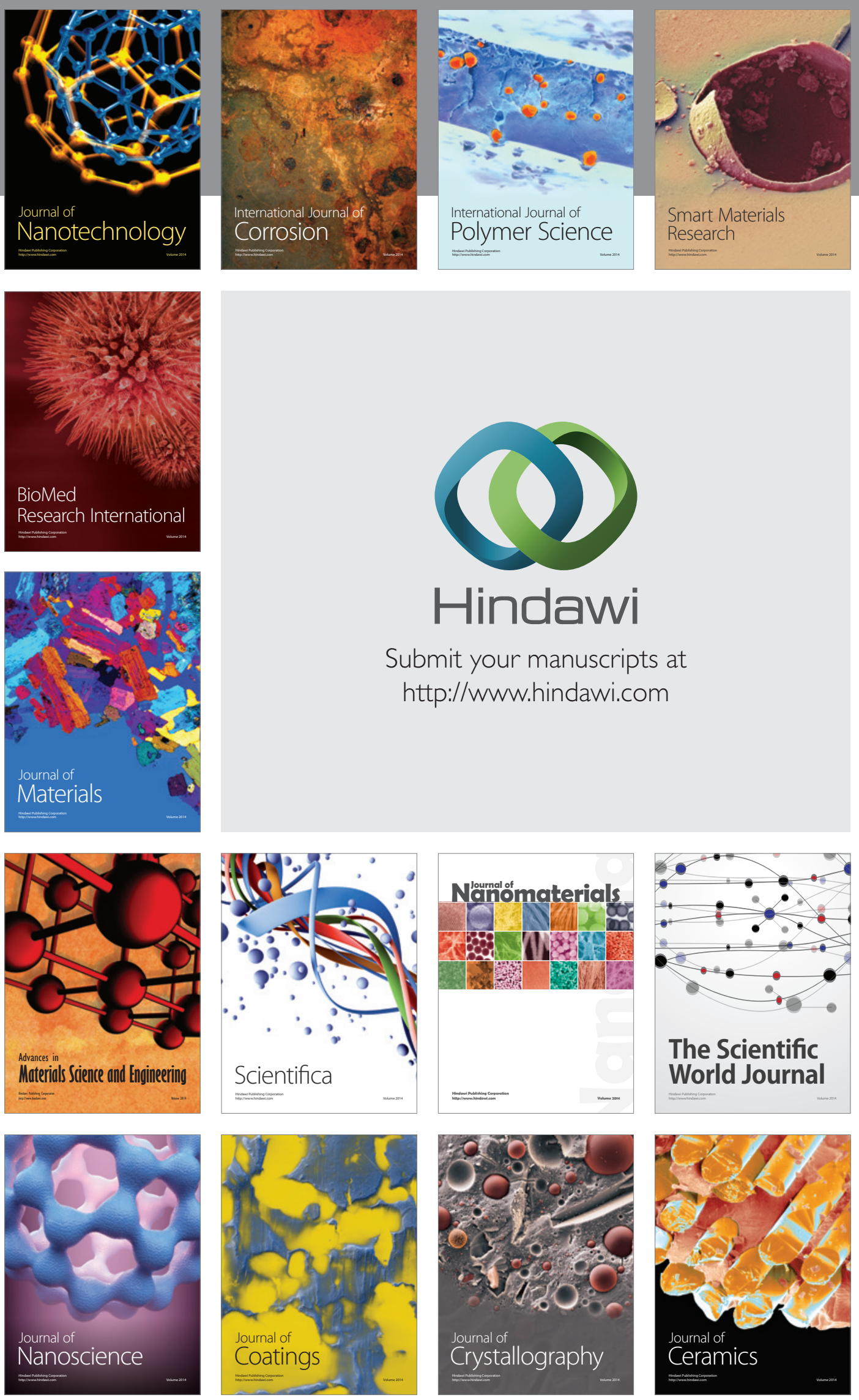

The Scientific World Journal

Submit your manuscripts at

http://www.hindawi.com

\section{World Journal}

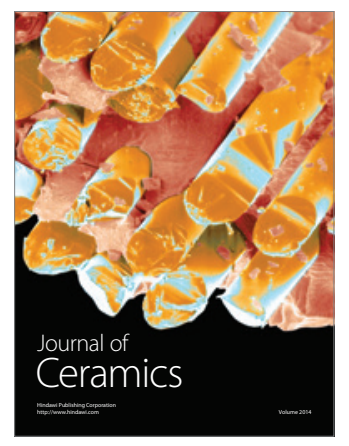

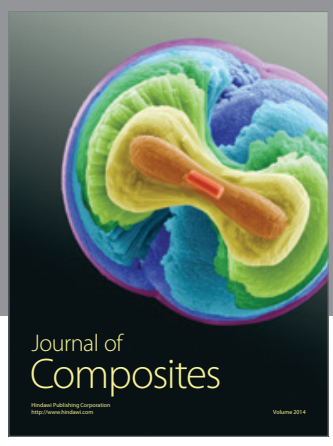
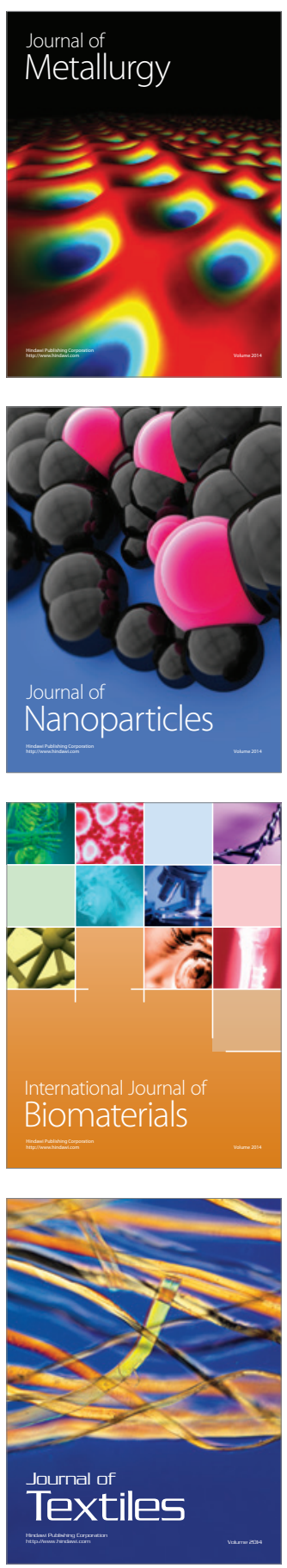